\title{
Biomolecular Interaction Study of Cyclolinopeptide A with Human Serum Albumin
}

\author{
Ben Rempel, ${ }^{1}$ Bo Gui, ${ }^{2}$ Jason Maley, ${ }^{3}$ Martin Reaney, ${ }^{4}$ and Ramaswami Sammynaiken ${ }^{1,3}$ \\ ${ }^{1}$ Department of Biochemistry, University of Saskatchewan, Saskatoon, SK, Canada S7N 5E5 \\ ${ }^{2}$ Department of Food and Bioproduct Sciences, University of Saskatchewan, Saskatoon, SK, Canada S7N 5A8 \\ ${ }^{3}$ Saskatchewan Structural Sciences Centre, University of Saskatchewan, Saskatoon, SK, Canada S7N 5C9 \\ ${ }^{4}$ Department Plant Sciences, University of Saskatchewan, Saskatoon, SK, Canada S7N 5A8 \\ Correspondence should be addressed to Jason Maley, j.maley@usask.ca and Ramaswami Sammynaiken, r.sammynaiken@usask.ca
}

Received 31 August 2010; Revised 4 December 2010; Accepted 21 December 2010

Academic Editor: Abdel A. Abdel-Rahman

Copyright () 2010 Ben Rempel et al. This is an open access article distributed under the Creative Commons Attribution License, which permits unrestricted use, distribution, and reproduction in any medium, provided the original work is properly cited.

The kinetics, energetics, and structure of Cyclolinopeptide A binding with Human Serum Albumin were investigated with surface plasmon resonance and circular dichroism. The complex is formed through slow recognition kinetics that is temperature sensitive in the range of $20^{\circ} \mathrm{C}-37^{\circ} \mathrm{C}$. The overall reaction was observed to be endothermic $\left(\Delta H=204 \mathrm{~kJ} \mathrm{~mol}^{-1}\right)$ and entropy driven $(\Delta S=$ $746 \mathrm{~J} \mathrm{~mol}^{-1} \mathrm{~K}^{-1}$ ) with overall small changes to the tertiary structure.

\section{Introduction}

The nutritional benefits of Linum usitatissium seed, more commonly known as flaxseed, are of significant interest as flax is seen as healthy [1]. Oil is the main constituent of flaxseed, with more than $70 \%$ of the oil composed of polyunsaturated fat. Flaxseed oil is the richest source of the essential omega-3 fatty acid, alpha-linolenic acid. Biotechnology and biomedicine around flax is developing its nutraceutical potential and thus contributes to the value added of the seed and oil [2-4]. Flaxseed is rich in nutrients, such as lignans which have been shown in laboratory studies to help protect against certain types of cancers [5-8]. In addition, flaxseed is a rich source of both soluble and insoluble fibers [1]. Flax also contains an abundance of hydrophobic cyclolinopeptides (CLPs), identified as cycloinopeptides A-I [9], to the extent that $500 \mathrm{mg}$ of CLPs are very easily extracted from $1000 \mathrm{~mL}$ of pressed oil [10].

Cyclolinopeptide A (CLP-A), a nonapeptide with a primary sequence of Pro-Pro-Phe-Phe-Leu-Ile-Ile-Leu-Val shown in Figure 1, was first isolated in 1959 from flaxseed oil precipitates [11]. The role of CLP-A and other CLPs in flax is unclear but in laboratory studies these peptides exhibit potent immunosuppressive activity [12], as well as inhibitory activity towards calcium-dependent activation of
T-lymphocyte cell division [13], as well as show antimalarial activity [14].

Depending on the peptide sequence, CLPs may have an abundance of $\mathrm{C}=\mathrm{O}, \mathrm{N}-\mathrm{H}$, and sulfur containing side chains, which could be used for linking drug delivery vessels. For instance, CLPs were synthesized with an even number of $\mathrm{D}$ and $\mathrm{L}$ amino acids, and were found to stack through intermolecular hydrogen bonding forming nanotubes with an antiparallel structure [15]. The amino acid residues are located on the exterior of the nanotube, which allows the outer surface properties to be optimized to its environment while the interior of the tube is uniform and adjustable by the number of amino acid residues inserted in the peptide. In another example, human serum albumin (HSA) was modified with the cyclic-RGD peptide and a PEG linker was used to link a previously "unlinkable" kinase inhibitor [16].

HSA is a globular protein and is the most abundant protein present in the blood plasma commonly occurring at concentrations of approximately $40 \mathrm{mg} \mathrm{mL}^{-1}$. It is a transport protein due to its interactions with many organic/inorganic compounds including fatty acids, giving it an important function of regulating intercellular fluxes [17]. HSA is composed of three structurally similar domains (I, II, and III), each contain 2 subdomains (A and B) which are stabilized by 17 disulfide bridges. In addition to the 7 binding 


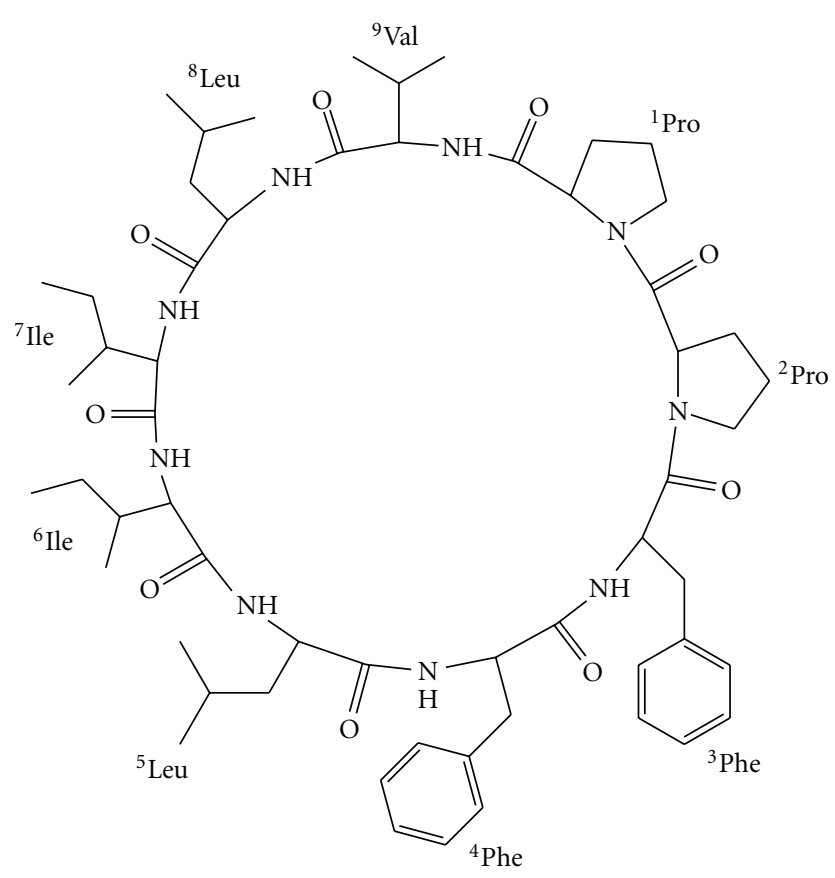

Figure 1: The structure of cyclolinopeptide A.

sites for fatty acids and a high affinity binding site on the $\mathrm{N}$-terminus, there are two hydrophobic pockets (generally referred to as site I and site II) located in subdomains IIA and IIIA [18].

Investigation of the thermodynamics and kinetics of CLP-A/HSA-binding and release is necessary when CLPs are considered as a potential drug/nutraceutical ingredient, or used as part of a potential nanodelivery device used for delivering materials to a targeted environment in biomedical applications. Here, we report the binding interaction of CLPA and HSA using surface plasmon resonance (SPR). Quantitative association $\left(K_{a}\right)$ and dissociation $\left(K_{d}\right)$ constants were obtained at different temperatures, which also allowed the determination of the thermodynamic parameters $(\Delta H, \Delta G$ and $\Delta S$ ) [19]. Circular dichroism (CD) in both the near-UV and far-UV was used to evaluate any conformational changes of HSA upon binding with the CLP-A [20].

\section{Materials and Methods}

2.1. Reagents. Amine coupling reagents ( $N$-ethyl- $N^{\prime}$-(dimethylaminopropyl)-carbodiimide (EDC), N-hydroxysuccinimide (NHS), Ethanolamine (EA)), HBS-EP (10 mM HEPES, $150 \mathrm{mM} \mathrm{NaCl}, 0.005 \%$ surfactant p20 and $3.4 \mathrm{mM}$ EDTA at pH 7.4) and CM5 carboxylated dextran sensor chips were obtained from Biacore (GE Healthcare, Montreal, QU). HSA (fatty acid free) was obtained from Sigma (Oakville, $\mathrm{ON})$. All other chemicals and solvents used were reagent grade.

CLP-A was extracted and purified from flaxseeds using a procedure previously reported [10]. Briefly, flaxseed (Linum usitatissimum L. cv. Bethune) was extracted using a continuous oilseed screw press (Komet, type CA59 C; IBG Monforts
Oekotec GmbH \& Co. Germany). to release the flaxseed oil. The oil was filtered, and placed under vacuum until CLP extraction. Flaxseed oil was diluted with 5\% ethyl acetate in hexane, loaded on a silica-gel column, and CLP's were separated from the oil by successive elutions of $10 \%(\mathrm{v} / \mathrm{v})$ ethyl acetate in hexane, $50 \%$ ethyl acetate in hexane, $100 \%$ ethyl acetate, $10 \%$ methanol in dichloromethane, and $20 \%$ methanol in dichloromethane. The resulting CLPs extracted from the flaxseed oil were further separated by reverse-phase HPLC using a gradient mixture of acetonitrile : water $(30: 70$ $(\mathrm{v} / \mathrm{v}))$, and increasing the acetonitrile to $65 \%$ over $120 \mathrm{~min}$. Fractions containing CLP-A were collected and freeze-dried. Approximately $180 \mathrm{mg}$ of CLP-A was isolated per $1000 \mathrm{~mL}$ of flaxseed oil. The purity of CLP-A was confirmed by NMR and mass spectrometry. The extracted CLP-A was recrystallized in methanol prior to the SPR and CD experiments detailed below.

2.2. Buffer and Analyte Preparation. Running buffer for all experiments was prepared by diluting a 10X phosphatebuffered saline (PBS) stock solution (100 mM phosphate buffer, $20.7 \mathrm{mM} \mathrm{KCl}, 1370 \mathrm{mM} \mathrm{NaCl}, \mathrm{pH}$ 6.7) to a $1 \mathrm{X} \mathrm{PBS}$, pH 7.4 solution containing 5\% DMSO. Running buffers were filtered and degassed daily before use.

Analyte solutions containing the CLP-A peptides were prepared by diluting the stock solution (10 $\mathrm{mM}$ in DMSO) into 1.05X PBS, giving a final 1X PBS, pH 7.4 buffer containing 5\% DMSO (same as the running buffer).

2.3. Surface Plasmon Resonance. All SPR measurements were performed at different temperatures using a BiacoreX instrument equipped with a research-grade CM5 carboxylateddextran sensor chip (Biacore). The fluidic unit of the instrument was cleaned prior to experiments using the DESORB method (injections of $0.5 \%$ sodium dodecyl sulphate, followed by $50 \mathrm{mM}$ glycine, $\mathrm{pH}$ 9.5) equipped in the instrument's software. On some occasions a "SUPER-CLEAN" method was also used (injections of $1 \% \mathrm{CH}_{3} \mathrm{COOH}, 1 \mathrm{M}$ $\mathrm{NaHCO}_{3}, 10 \mathrm{mM} \mathrm{HCl}$, and $6 \mathrm{M} \mathrm{GndHCl}$ ).

The carboxylated-dextran sensor chips were preconditioned prior to HSA immobilization by priming the instrument 3 times with HBS-EP buffer, followed by 3 successive $1 \mathrm{~min}$ injections of $50 \mathrm{mM} \mathrm{NaOH}$ at $50 \mu \mathrm{L} \mathrm{min}{ }^{-1}$. HSA was covalently immobilized onto a CM5 sensor surface at $25^{\circ} \mathrm{C}$ using standard amine-coupling chemistry [21]. Flow cell $1(\mathrm{Fc} 1)$ and flow cell $2(\mathrm{Fc} 2)$ were activated by a 7 min injection of a $1: 1$ mixture of $0.1 \mathrm{M}$ NHS and $0.4 \mathrm{M}$ EDC using a flow rate of $5 \mu \mathrm{L} \mathrm{min}^{-1}$. Immediately after activation, HSA ( $30 \mu \mathrm{g} \mathrm{mL}^{-1}, 10 \mathrm{mM}$ acetate buffer $\mathrm{pH} 5.3$ ) was immobilized onto Fc2. A 7 min injection of $1 \mathrm{M}$ EA ( $\mathrm{pH} 8.5$ ) was conducted over Fc1 and Fc2 to deactivate the surfaces. The final HSA concentration immobilized onto the chip was 9-11 kRU.

CLP-A solutions (50-200 $\mu \mathrm{M})$ were injected in triplicate and flowed over reference and HSA surfaces for $2 \mathrm{~min}$ at a flow rate of $30 \mu \mathrm{M} \mathrm{min}^{-1}$, followed by a dissociation phase of $3 \mathrm{~min}$ for all experimental temperatures. At the end of the CLP-A injection, the flowing solution was switched 
to the running buffer until the response returned to the original baseline. Instances where the baseline was not readily achieved, a short pulse of $50 \%(\mathrm{v} / \mathrm{v})$ DMSO solution was injected at high flow rate to remove any remaining CLP-A. Data were collected at a rate of $5 \mathrm{~Hz}$ and processed using the BiaEvaluation V4.2 software. The equilibrium constant, $K_{a}$, was determined using the rectangular hyperbola equation [20]:

$$
R_{\mathrm{eq}}=R_{\max } \frac{K_{a}[\text { CLP-A }]}{1+K_{a}[\text { CLP-A }]},
$$

where $R_{\mathrm{eq}}, R_{\max },[\mathrm{CLP}-\mathrm{A}]$ are the measured response values, the binding site saturation value, and the concentration of CLP-A, respectively. Curve-fitting was done with Microcal Origin V7.1 using a global $R_{\max }$ value of 2000 .

2.4. Circular Dichroism. CD measurements of HSA $(18 \mu \mathrm{M})$, HSA/CLP-A $(18 \mu \mathrm{M}, 50 \mu \mathrm{M})$ in $10 \mathrm{mM}$ PBS, 5\% DMSO, pH = 7.4 buffer were made with a Pistar-180 CD spectrometer (Applied Photophysics Ltd., Leatherhead, UK) at room temperature. The far-UV region was scanned from 260$180 \mathrm{~nm}$ in $0.5 \mathrm{~nm}$ steps at a scan rate of $10 \mathrm{~nm} \mathrm{~min}^{-1}$ and a bandwidth of $6 \mathrm{~nm}$ using a $0.010 \mathrm{~cm}$ optical pathlength quartz cuvette. The secondary structure was estimated using the neural network deconvolution software CDNN V2.1 [22]. The near-UV region was scanned from $350-250 \mathrm{~nm}$ in $0.5 \mathrm{~nm}$ steps at a scan rate of $10 \mathrm{~nm} \mathrm{~min}{ }^{-1}$, and a bandwidth of $2 \mathrm{~nm}$ using a $10 \mathrm{~mm}$ optical pathlength cuvette.

\section{Results and Discussion}

Typical SPR response sensorgrams of CLP-A-binding interaction with HSA which was covalently immobilized onto a carboxylated dextran gold-coated sensor surface via amine coupling are shown in Figure 2. The response of CLP-A for concentrations ranging between $50 \mu \mathrm{M}$ and $200 \mu \mathrm{M}$ are shown at $20^{\circ} \mathrm{C}, 25^{\circ} \mathrm{C}, 30^{\circ} \mathrm{C}$, and $37^{\circ} \mathrm{C}$ in Figures $2(\mathrm{a}), 2(\mathrm{~b})$, $2(\mathrm{c})$, and 2(d), respectively. The gradual increase of response to a steady state during CLP-A injection indicates very slow recognition kinetics of the CLP-A to the HSA-binding site. Quantitative kinetic data were initially extracted using the kinetics profiling within the Biacore Evaluation software. Increased concentration of CLP-A resulted in an increased response suggesting that the saturation point of HSA was not reached within the concentration range of CLP-A used. The slow recognition and possible rate limiting step is due to cyclic peptide becoming available for interaction with HSA. The CLP-A has a large hydration sphere which dissociates before interaction with HSA. This process requires energy and also increases the entropy [19].

HSA has seven known fatty-acid-binding sites, each of which is known to bind other types of small molecules [17]. Two of the more common binding sites for small molecule drugs are commonly known as Sudlow's site I (i.e. the warfarin-binding site), and Sudlow's site II (the benzodiazapene site). Entropy-driven Site I bound drug molecules, which are structurally bulky, heterocyclic compounds with centrally localized negative polar/charges and
TABLE 1: CLP-A/HSA equilibrium binding constants determined from SPR sensorgrams.

\begin{tabular}{lccc}
\hline Temperature $\left({ }^{\circ} \mathrm{C}\right)$ & $K_{a}{ }^{(\mathrm{a})}\left(\mathrm{M}^{-1}\right)$ & $K_{d}{ }^{(\mathrm{b})}(\mu \mathrm{M})$ & $\chi^{2}$ \\
\hline 20 & $757(33)$ & 1321 & 4.5 \\
25 & $1687(20)$ & 593 & 1.9 \\
30 & $7056(36)$ & 142 & 1.6 \\
\hline 37 & $50032(1792)$ & 20 & 10.2 \\
\hline (a) determined from curve-fitting dose-response curves (Figure 3) with (1). \\
$\begin{array}{l}\text { The standard error from curve-fitting are given in brackets. } \\
\text { (b) } K_{d}=1 / K_{a} .\end{array}$
\end{tabular}

TABle 2: Secondary structure evaluation from far-UV cirular dichroism spectra. ${ }^{\text {(a) }}$

\begin{tabular}{lcc}
\hline Secondary Structure & HSA $^{(\mathrm{b})}(\%)$ & HSA/CLP-A $^{(\mathrm{b})}(\%)$ \\
\hline Helix & 46 & 41 \\
Antiparallel & 8 & 9 \\
Parallel & 6 & 6 \\
Beta-Turn & 15 & 16 \\
Rndm. Coil & 27 & 29 \\
\hline Total Sum & 102 & 101 \\
\hline (a) CDNN V2.1 software was used to evaluate the secondary structure using \\
the "complex" spectra category and the $210-260$ nm region of the spectra. \\
(b) HSA $(18 \mu \mathrm{M})$, and HSA/CLA $(18 \mu \mathrm{M}, 50 \mu \mathrm{M})$ were in in $10 \mathrm{mM}$ PBS, $5 \%$ \\
DMSO, pH = 7.4 buffer.
\end{tabular}

hydrophobic substitutions, have been suggested to bind through hydrophobic interactions and/or must be bound in a hydrophobic crevice within the binding cavity [23].

Dose-response curves taken at different temperatures are shown in Figure 3. CLP-A concentration was limited to below $200 \mu \mathrm{M}$ due to the solubility of the peptide in the buffer. The affinity of interaction was estimated by first assuming that HSA-binding sites were equally available and second that only high affinity sites were occupied in the working concentration range [24]. The data sets shown in Figure 3 were fit to (1), and the $K_{a}$ and $K_{d}$ values are summarized in Table 1 . The $K_{d}$ and $K_{a}$ values indicate that affinity increases as the temperature increased. The shape of the sensorgram as the temperature increases shows that in addition to the increase in affinity with temperature there is also a change in recognition before steady state is reached. The kinetic information shows that there is slower association and faster dissociation at $25^{\circ} \mathrm{C}$ compared to the values at $37^{\circ} \mathrm{C}$. This suggests that there is larger binding at the higher temperature. The faster release at the lower temperature suggests that thermodynamic parameters would also be important in understanding this binding. The fast dissociation at $25^{\circ} \mathrm{C}$ and the slower dissociation at $37^{\circ} \mathrm{C}$ show that $12^{\circ} \mathrm{C}$ change contribute significantly to reaching the activation energy. The larger binding at higher temperatures indicates that the activation energy is relatively low. To further elucidate the HSA/CLP-A interaction, thermodynamic parameters are extracted using the van't Hoff equation

$$
\ln K_{d}=\frac{\Delta H}{R}\left(\frac{1}{T}\right)-\frac{\Delta S}{R},
$$




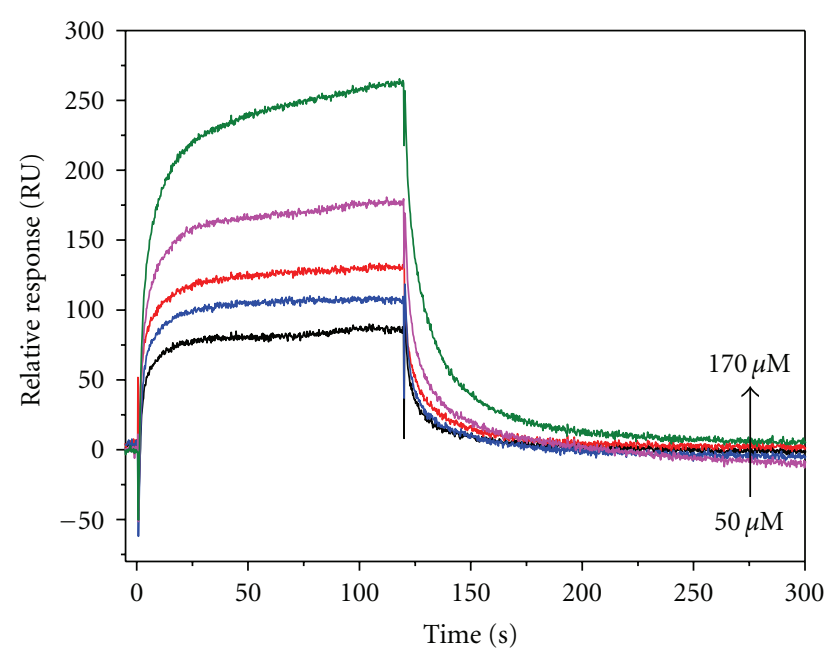

(a)

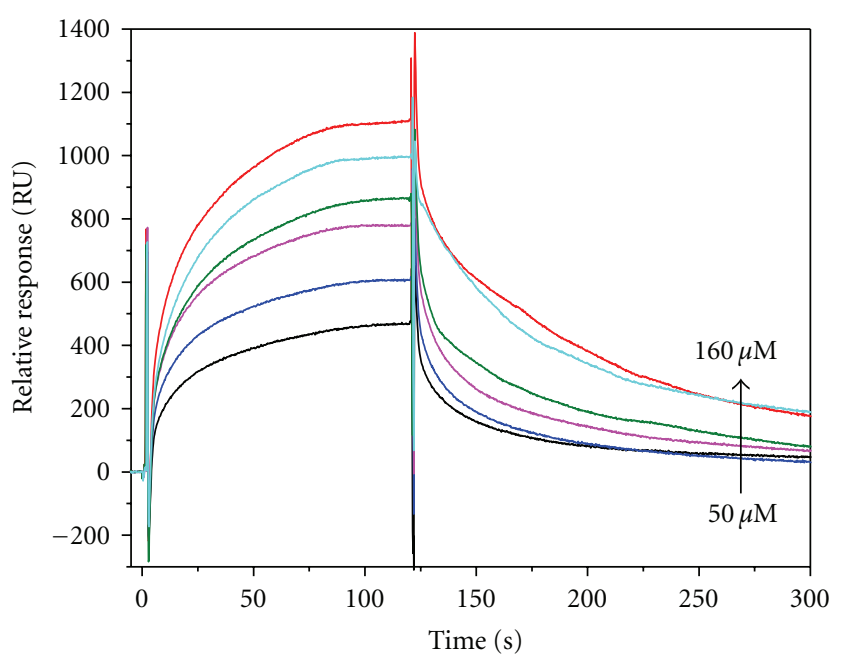

(c)

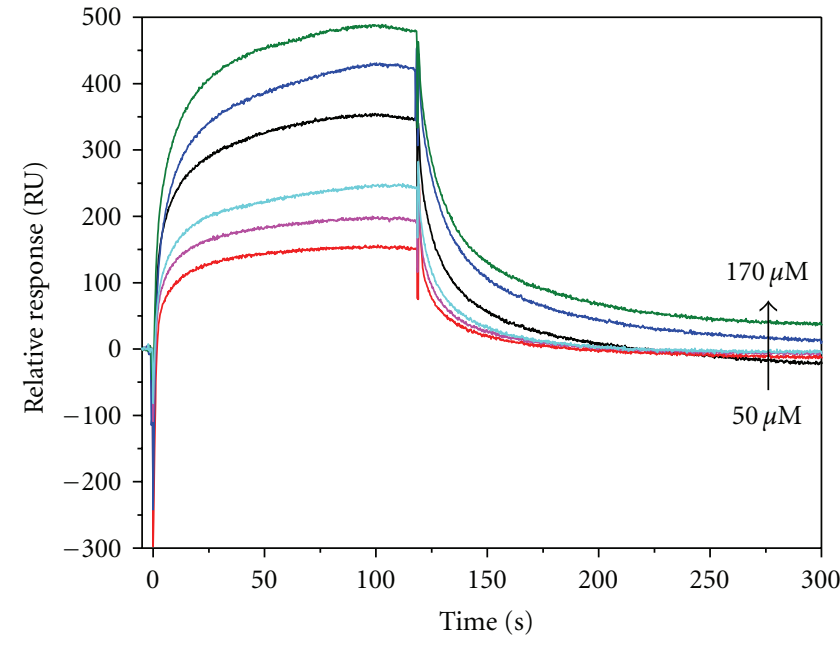

(b)

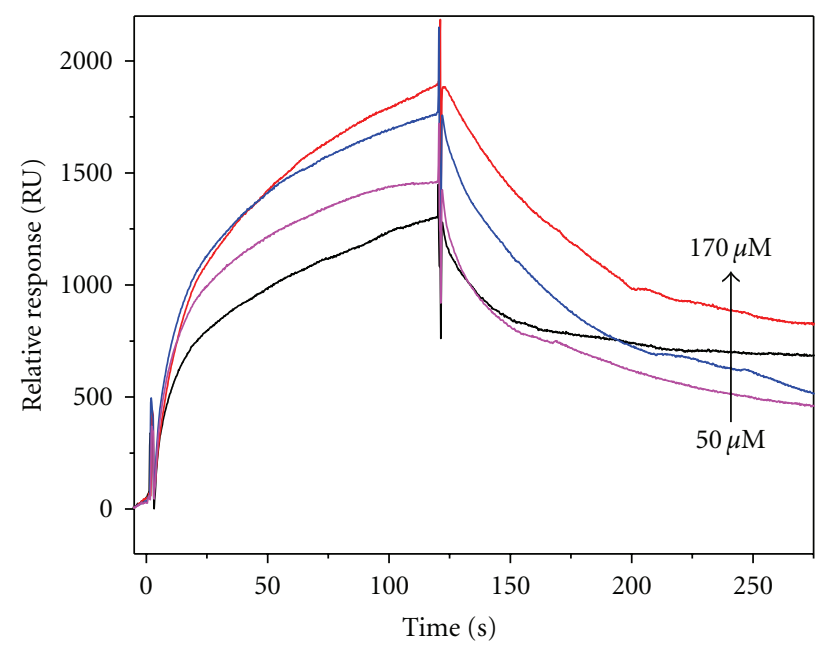

(d)

Figure 2: Representative SPR sensorgram responses for CLP-A $(50-200 \mu \mathrm{M})$ binding to HSA at (a) $20^{\circ} \mathrm{C},\left(\right.$ b) $25^{\circ} \mathrm{C},(\mathrm{c}) 30^{\circ} \mathrm{C},(\mathrm{d}) 37^{\circ} \mathrm{C}$. Experiments performed at each temperature were independent experiments and each experiment was repeated.

where $R=8.314 \mathrm{~J} \mathrm{~mol}^{-1} \mathrm{~K}^{-1}$. A plot of $\ln K_{d}$ versus $T^{-1}$ shown in Figure 4 is linear. This yields $\Delta H$ and $\Delta S$ for the interaction to be $204 \mathrm{~kJ} \mathrm{~mol}^{-1}$ and $746 \mathrm{~J} \mathrm{~mol}^{-1} \mathrm{~K}^{-1}$ respectively [19]. The binding is overall endothermic. This indicates an association with the hydrophobic pockets of HSA and the opening of binding sites. Moreover, DMSO has been used to assist the solubility. Therefore, the entire solvation complex consisting of CLP-A, DMSO and $\mathrm{H}_{2} \mathrm{O}$ requires energy to expose the binding site. This energy plus the binding energy for interaction in the hydrophobic pockets of HSA result in an overall endothermic process. The large entropy of the endothermic process clearly indicate that binding is entropy-driven. This is due to contribution from breaking of the solvation complex and hydrophobic binding.

Thermodynamic investigation of several anionic drug binding to HSA has been reported. It was found that the Site II bound drugs formed enthalpy driven complexes (large- $\Delta H$, large- $\Delta S$ ) whereas Site I bound drugs produced more entropy-driven complexes (small- $\Delta H$, minimal negative or positive $\Delta S$ ). Interestingly, the $\Delta G$ value for all drug molecules was approximately constant $\left(-30 \mathrm{~kJ} \mathrm{~mol}^{-1}\right.$ at $37^{\circ} \mathrm{C}$ ) [25]. For the CLP-A HSA interaction, the calculated $\Delta G$ is approximately $-27 \mathrm{~kJ} \mathrm{~mol}^{-1}$ (at $37^{\circ} \mathrm{C}$ ), which is slightly lower compared to the anionic drugs. However, this $\Delta G$ value is comparable to values reported for short-medium chain (C4-C8) fatty acid-binding to HSA ( -26 to $-28 \mathrm{~kJ} \mathrm{~mol}^{-1}$ at $37^{\circ} \mathrm{C}$ ) [23]. These fatty acids were found to bind in only one class of binding sites of HSA at a ratio of $2: 1$. The binding process formed enthalpy driven complexes, reflecting van der Waals and/or hydrogen binding in low dielectric media.

Presently, it is unclear as to the role of individual amino acids or possible sequence that play a primary role for CLP-A's binding with HSA. Research involving other CLPs (CLP-B, CLP-E) and some of their modified counterparts is currently ongoing. Previous studies involving the biological 


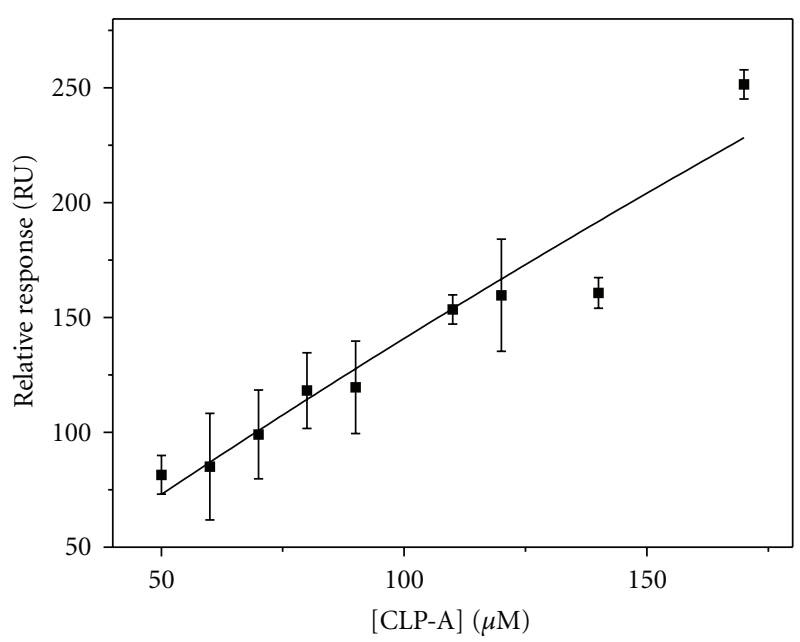

(a)

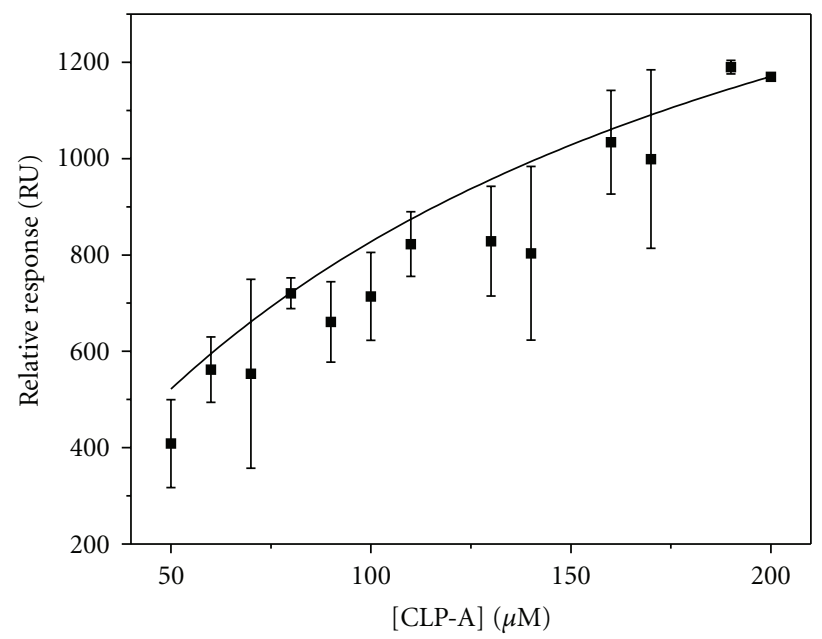

(c)

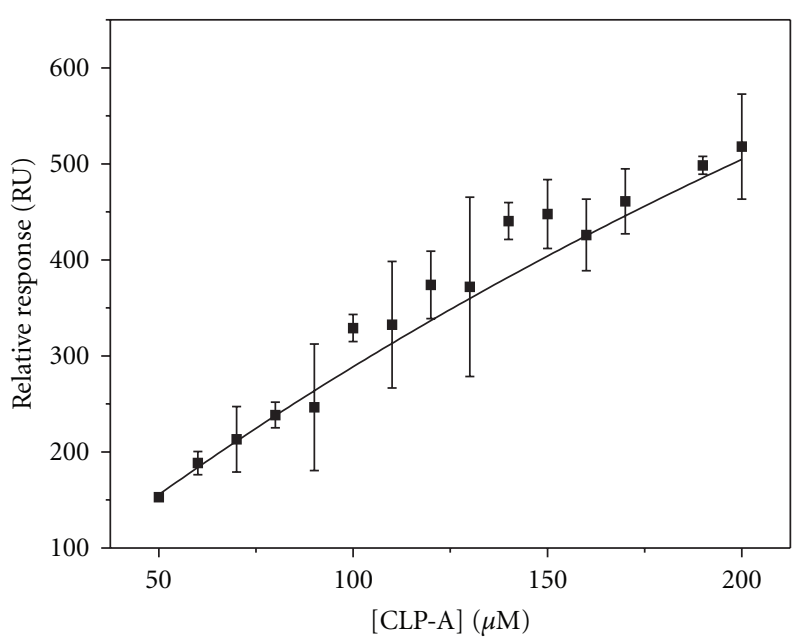

(b)

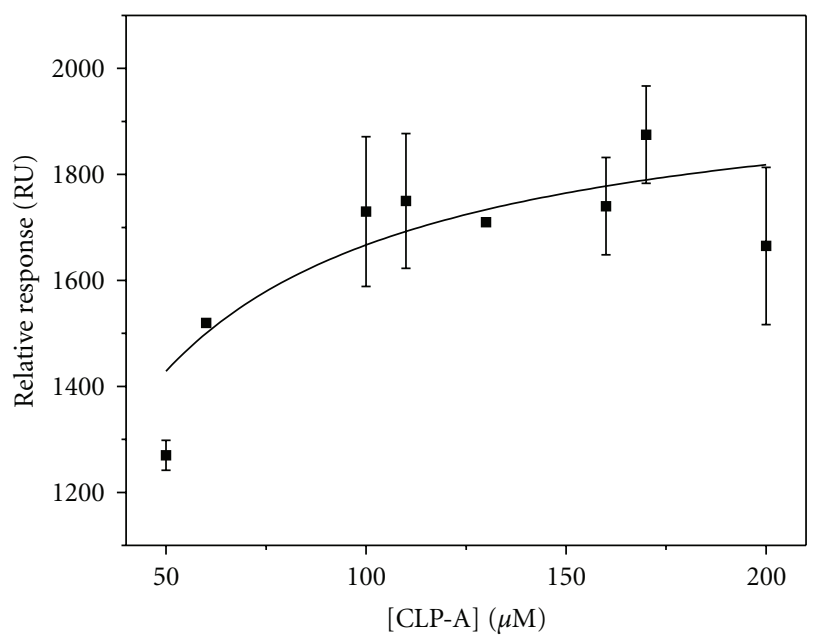

(d)

Figure 3: Dose-response curves of CLP-A (50-250 $\mu \mathrm{M}$ ) binding to HSA at (a) $20^{\circ} \mathrm{C}$, (b) $25^{\circ} \mathrm{C}$, (c) $30^{\circ} \mathrm{C}$, (d) $37^{\circ} \mathrm{C}$. Curves were curve-fitted with (2) to obtain $K_{a}$ of the interaction. Error bars are the standard deviation taken from 3 measurements.

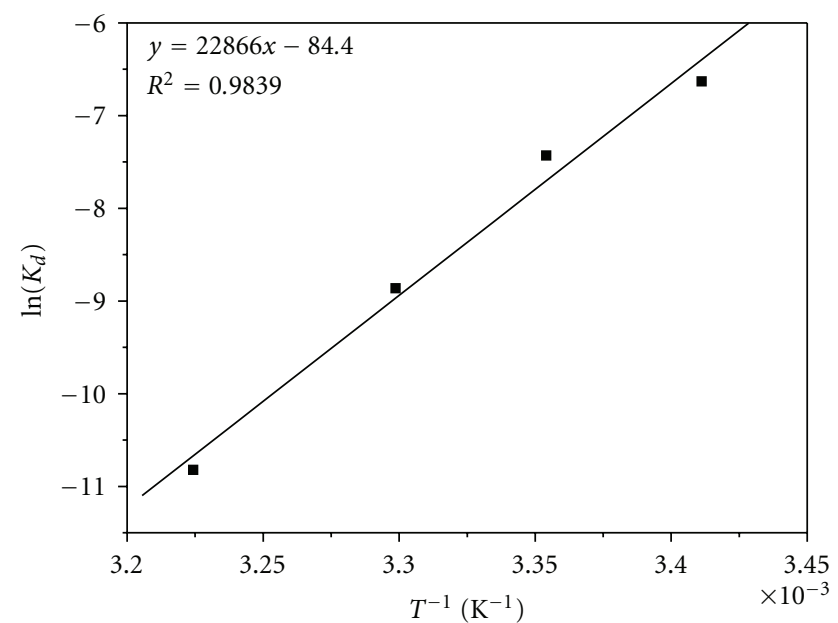

FIgURE 4: Thermodynamic parameters for the CLP-A-binding interaction to HSA are determined by the van't Hoff equation (3). activity of this peptide has shown that the-Pro-Phe-Phetripeptide block played an important role in its ability to inhibit cholate uptake into hepatocytes [26]. Other studies have found that the CLP-A has immunosuppressive activity [12], and many structural analogues have been synthesized to study the peptide sequence's role [27]. It was concluded that the flexibility of the peptide structure plays an important role in its biological function. Other work has focused on increasing the solubility of CLP-A without suppressing its biological activity [28]. It was determined that substitution of the Phe residues with their sulfonated derivates for CLP-A and its linear and cyclic derivatives maintained their immunosuppresor activity. For the current study, it could be speculated that increasing the solubility of CLP-A would reduce the overall solvation complex, which would reduce the thermodynamic parameters of the CLP-A/HSA interaction.

Another interesting feature observed from the SPR data was that the measured $R_{\mathrm{eq}}$ for a given concentration of 


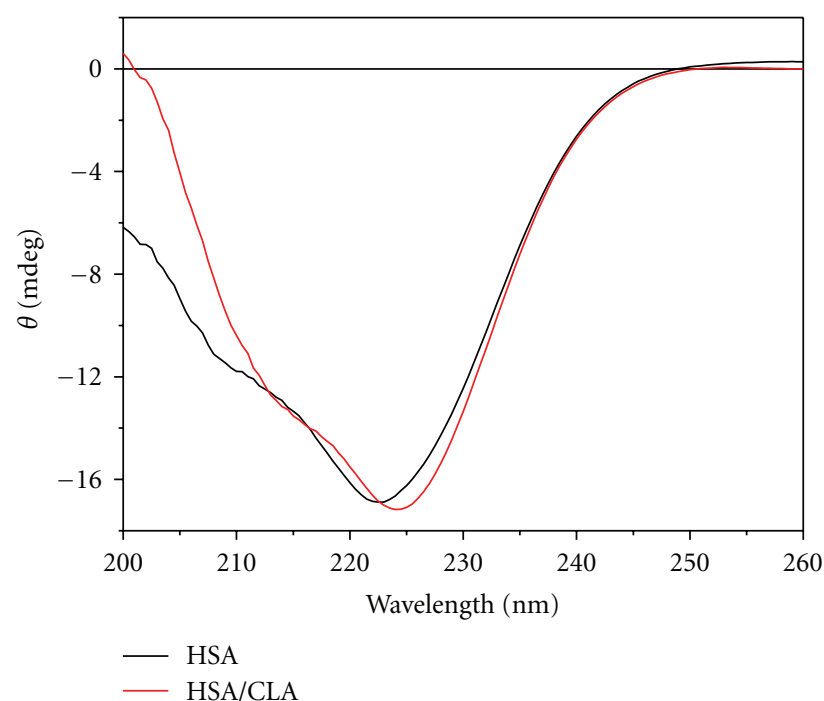

(a)

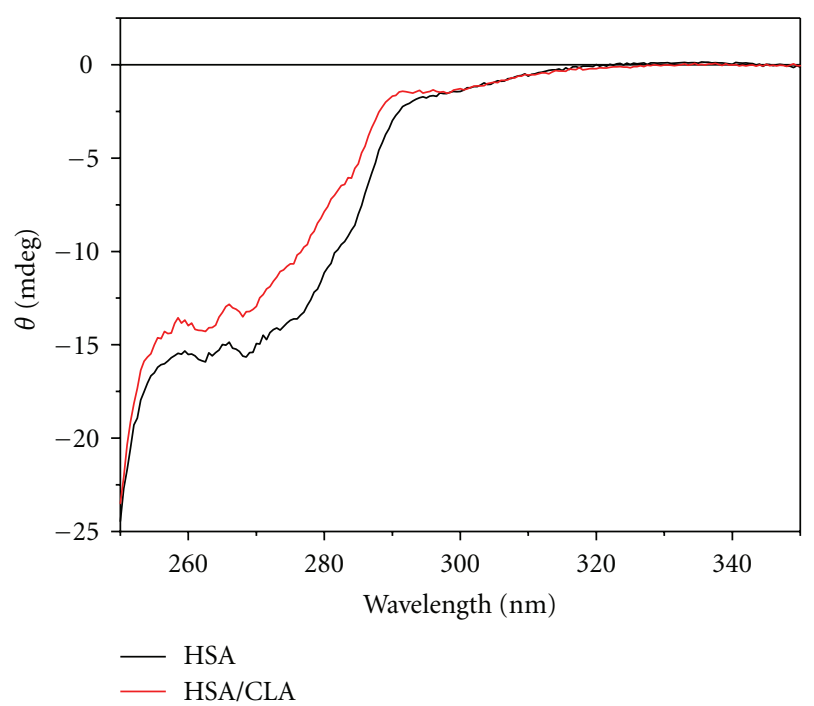

(b)

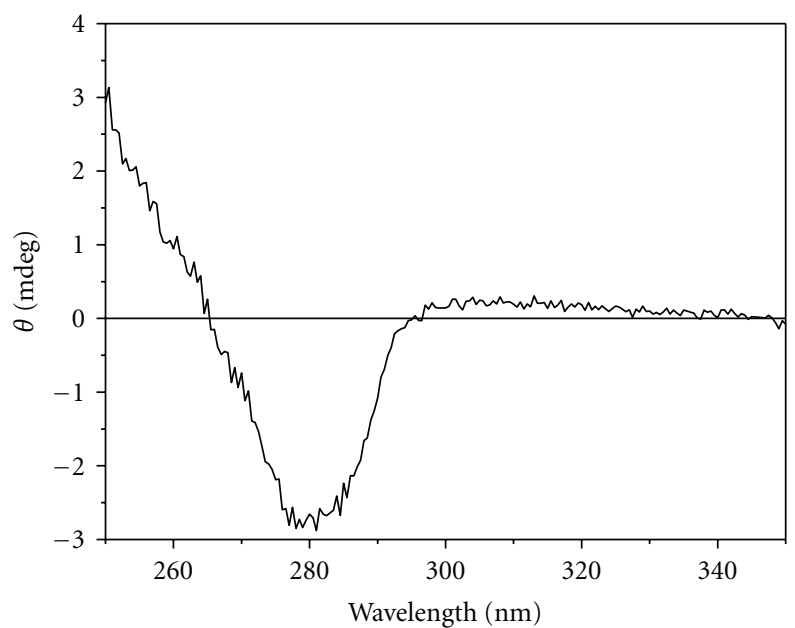

(c)

Figure 5: Circular dichroism spectra of HSA $(18 \mu \mathrm{M})$, and HSA/CLA $(18 \mu \mathrm{M}, 50 \mu \mathrm{M})$ in $10 \mathrm{mM}$ PBS, $5 \%$ DMSO, pH $=7.4$ buffer taken in the (a) far-UV and (b) near-UV spectral region. Spectra were an average of 4 spectra, and respective background spectra were subtracted accordingly. (c) Difference CD spectrum of HSA $(18 \mu \mathrm{M})$, and HSA/CLA $(18 \mu \mathrm{M}, 50 \mu \mathrm{M})$ solutions for the near-UV region indicates some conformational changes after CLP-A-binding.

CLP-A also increased with temperature. Given that the HSA surface concentration was approximately $11 \mathrm{kRU}$, one can estimate that the theoretical $R_{\max }$ for this binding interaction is approximately $160 \mathrm{RU}$ using the relation:

$$
R_{\max }^{\text {theoretical }}=\frac{\mathrm{MW}_{a}}{\mathrm{MW}_{L}} * R_{L} * S_{m},
$$

where $\mathrm{MW}_{a}, \mathrm{MW}_{L}$ are the molecular weights of the analyte and ligand, respectively, $R_{L}$ is the surface density of ligand, and $S_{m}$ is the stoichiometry of the interaction. From (3), the increase in the given response could be due to peptide aggregation, or additional binding to other active binding sites on the HSA. It should be noted that SPR is measuring a change in the refractive index at the sensor surface, and this will be affected by temperature change, although it should not be significant in this narrow temperature range.
Conformational changes of proteins can also change SPR responses [29].

In order to assess if any conformational changes were present upon CLP-A complexation with HSA, we compared the far-UV and near-UV CD spectra of HSA and HSA/CLP$A$ in the running buffer used in the Biacore experiments shown in Figure 5. CD spectra taken in the far-UV spectral region provide insight to the secondary structure of a protein. In Figure 5(a), we observe that the $\mathrm{CD}$ spectrum for the HSA/CLP-A complex has a slightly different lineshape compared to the native HSA CD spectrum, suggesting that there are slight changes to the secondary structure of HSA upon CLP-A-binding. The secondary structure of HSA was evaluated using the CDNN deconvolution software [22], and the resulting secondary components are summarized in Table 2 . The secondary structure results indicate the $\alpha$-helix 
content of HSA decreases slightly upon the binding of CLPAThere are also some significant changes in the near-UV CD spectra shown in Figure 5(b). This region of the spectra corresponds to signals from the phenylalanine, tyrosine, and tryptophan residues on the protein and it provides insight to changes in the tertiary structure of the protein. The observed change in $\mathrm{CD}$ signal indicates a tertiary conformational change upon CLP-A-binding, shown in Figure 5(c).

\section{Conclusions}

The CLP-A/HSA interaction investigated by SPR shows the complex is formed by a strong endothermic and entropydriven reaction. This entropy-driven complexation indicates that the interaction occurs through a hydrophobic interaction of the CLP-A and possibly Sudlow site I of the HSA. Complex formation is through slow recognition kinetics and is relative stable at physiological temperatures. A slight change in both secondary and tertiary structure of HSA are observed upon the binding of CLP-A. Although there are still many potential questions that remain regarding the binding of CLP-A to HSA, the fact that quantitative thermodynamic and binding constants has been demonstrated can help lay the foundation for the future development of any potential biomedical applications involving CLP-A. This would add to understanding the nutraceutical potential of CLP-A and CLP in general.

\section{Acknowledgments}

This work was supported by grants from Natural Sciences and Engineering Research Council (NSERC), Agricultural Development Fund (Saskatchewan Ministry of Agriculture). M. Reaney holds a Saskatchewan Ministry of Agriculture Strategic Research Chair position in Lipid Quality and Utilization. Biacore and CD measurements were done at the Saskatchewan Structural Sciences Centre, which is supported by the University of Saskatchewan. Thanks are also extended to the referees for their critical and helpful comments.

\section{References}

[1] B. D. Oomah, "Flaxseed as a functional food source," Journal of the Science of Food and Agriculture, vol. 81, no. 9, pp. 889-894, 2001.

[2] B. D. Oomah and G. Mazza, "Bioactive components of flaxseed: occurrence and health benefits," 2000.

[3] J. Rajesha, K. N. C. Murthy, M. K. Kumar, B. Madhusudhan, and G. A. Ravishankar, "Antioxidant potentials of flaxseed by in vivo model," Journal of Agricultural and Food Chemistry, vol. 54, no. 11, pp. 3794-3799, 2006.

[4] C. M. Bassett, D. Rodriguez-Leyva, and G. N. Pierce, "Experimental and clinical research findings on the cardiovascular benefits of consuming flaxseed," Applied Physiology, Nutrition and Metabolism, vol. 34, no. 5, pp. 965-974, 2009.

[5] A. L. Bhatia, A. Sharma, S. Patni, and A. L. Sharma, "Prophylactic effect of flaxseed oil against radiation-induced hepatotoxicity in mice," Phytotherapy Research, vol. 21, no. 9, pp. 852-859, 2007.
[6] J. Waldschläger, C. Bergemann, W. Ruth et al., "Flax-seed extracts with phytoestrogenic effects on a hormone receptorpositive tumour cell line," Anticancer Research, vol. 25, no. 3, pp. 1817-1822, 2005.

[7] J. B. Goodnough, "Antitumorigenic effects of flaxseed and its lignan, secoisolariciresinol diglycoside (SDG)," Nutrition Bytes, vol. 10, no. 1, 2005.

[8] J. M. Bergman, L. U. Thompson, and C. Dabrosin, "Flaxseed and its lignans inhibit estradiol-induced growth, angiogenesis, and secretion of vascular endothelial growth factor in human breast cancer xenografts in vivo," Clinical Cancer Research, vol. 13, no. 3, pp. 1061-1067, 2007.

[9] B. Picur, M. Cebrat, J. Zabrocki, and I. Z. Siemion, "Cyclopeptides of Linum usitatissimum," Journal of Peptide Science, vol. 12, no. 9, pp. 569-574, 2006.

[10] M. J. Reaney, WO Patent 2009079792.

[11] H. P. Kaufmann and A. Tobschirbel, "An oligopeptide from linseed," Chemische Berichte, vol. 92, pp. 2805-2809, 1959.

[12] Z. Wieczorek, B. Bengtsson, J. Trojnar, and I. Z. Siemion, "Immunosuppressive activity of cyclolinopeptide A," Peptide Research, vol. 4, no. 5, pp. 275-283, 1991.

[13] T. J. Gaymes, M. Cebrat, I. Z. Siemion, and J. E. Kay, "Cyclolinopeptide A (CLA) mediates its immunosuppressive activity through cyclophilin-dependent calcineurin inactivation," FEBS Letters, vol. 418, no. 1-2, pp. 224-227, 1997.

[14] A. Bell, P. M. McSteen, M. Cebrat, B. Picur, and I. Z. Siemion, "Antimalarial activity of cyclolinopeptide A and its analogues," Acta Poloniae Pharmaceutica, vol. 57, pp. 134-136, 2000.

[15] M. R. Ghadiri, J. R. Granja, R. A. Milligan, D. E. McRee, and N. Khazanovich, "Self-assembling organic nanotubes based on a cyclic peptide architecture," Nature, vol. 366, no. 6453, pp. 324-327, 1993.

[16] K. Temming, M. Lacombe, R. Q. J. Schaapveld et al., "Rational design of RGD-albumin conjugates for targeted delivery of the VEGF-R kinase inhibitor PTK787 to angiogenic endothelium," ChemMedChem, vol. 1, no. 11, pp. 1200-1203, 2006.

[17] P. Ascenzi, A. Bocedi, S. Notari, G. Fanali, R. Fesce, and M. Fasano, "Allosteric modulation of drug binding to human serum albumin," Mini-Reviews in Medicinal Chemistry, vol. 6, no. 4, pp. 483-489, 2006.

[18] J. Ghuman, P. A. Zunszain, I. Petitpas, A. A. Bhattacharya, M. Otagiri, and S. Curry, "Structural basis of the drug-binding specificity of human serum albumin," Journal of Molecular Biology, vol. 353, no. 1, pp. 38-52, 2005.

[19] P. W. Atkins, Atkins' Physical Chemistry, W.H. Freeman, New York, NY, USA, 2006.

[20] K. E. van Holde, W. C. Johnson, and P. S. Ho, Principles of Physical Biochemistry, Pearson/Prentice Hall, Upper Saddle River, NJ, USA, 2006.

[21] B. Johnsson, S. Lofas, and G. Lindquist, "Immobilization of proteins to a carboxymethyldextran-modified gold surface for biospecific interaction analysis in surface plasmon resonance sensors," Analytical Biochemistry, vol. 198, no. 2, pp. 268-277, 1991.

[22] G. Bohm, R. Muhr, and R. Jaenicke, "Quantitative analysis of protein far UV circular dichroism spectra by neural networks," Protein Engineering, vol. 5, no. 3, pp. 191-195, 1992.

[23] H. Aki and M. Yamamoto, "Thermodynamic characterization of drug binding to human serum albumin by isothermal titration microcalorimetry," Journal of Pharmaceutical Sciences, vol. 83, no. 12, pp. 1712-1716, 1994.

[24] A. Frostell-Karlsson, A. Remaeus, H. Roos et al., "Biosensor analysis of the interaction between immobilized human serum albumin and drug compounds for prediction of human serum 
albumin binding levels," Journal of Medicinal Chemistry, vol. 43, no. 10, pp. 1986-1992, 2000.

[25] H. Aki, M. Goto, and M. Yamamoto, "Thermodynamic aspects of the molecular recognition of drugs by human serum albumin,” Thermochimica Acta, vol. 251, pp. 379-388, 1995.

[26] H. Kessler, M. Klein, A. Mueller et al., "Conformational prerequisites for the in vitro inhibition of cholate absorption in hepatocytes by cyclic antamanide and somatostatin analogs," Angewandte Chemie International Edition, vol. 98, pp. 10301032, 1986.

[27] E. Benedetti and C. Pedone, "Cyclolinopeptide A: inhibitor, immunosuppressor or other?" Journal of Peptide Science, vol. 11, no. 5, pp. 268-272, 2005.

[28] M. Cebrat, M. Lisowski, I. Z. Siemion, M. Zimecki, and Z. Wieczorek, "Sulfonated analogues of cyclolinopeptide A: synthesis, immunosuppressive activity and CD studies," Journal of Peptide Research, vol. 49, no. 5, pp. 415-420, 1997.

[29] T. Mannen, S. Yamaguchi, J. Honda, S. Sugimoto, A. Kitayama, and T. Nagamune, "Observation of charge state and conformational change in immobilized protein using surface plasmon resonance sensor," Analytical Biochemistry, vol. 293, no. 2, pp. 185-193, 2001. 

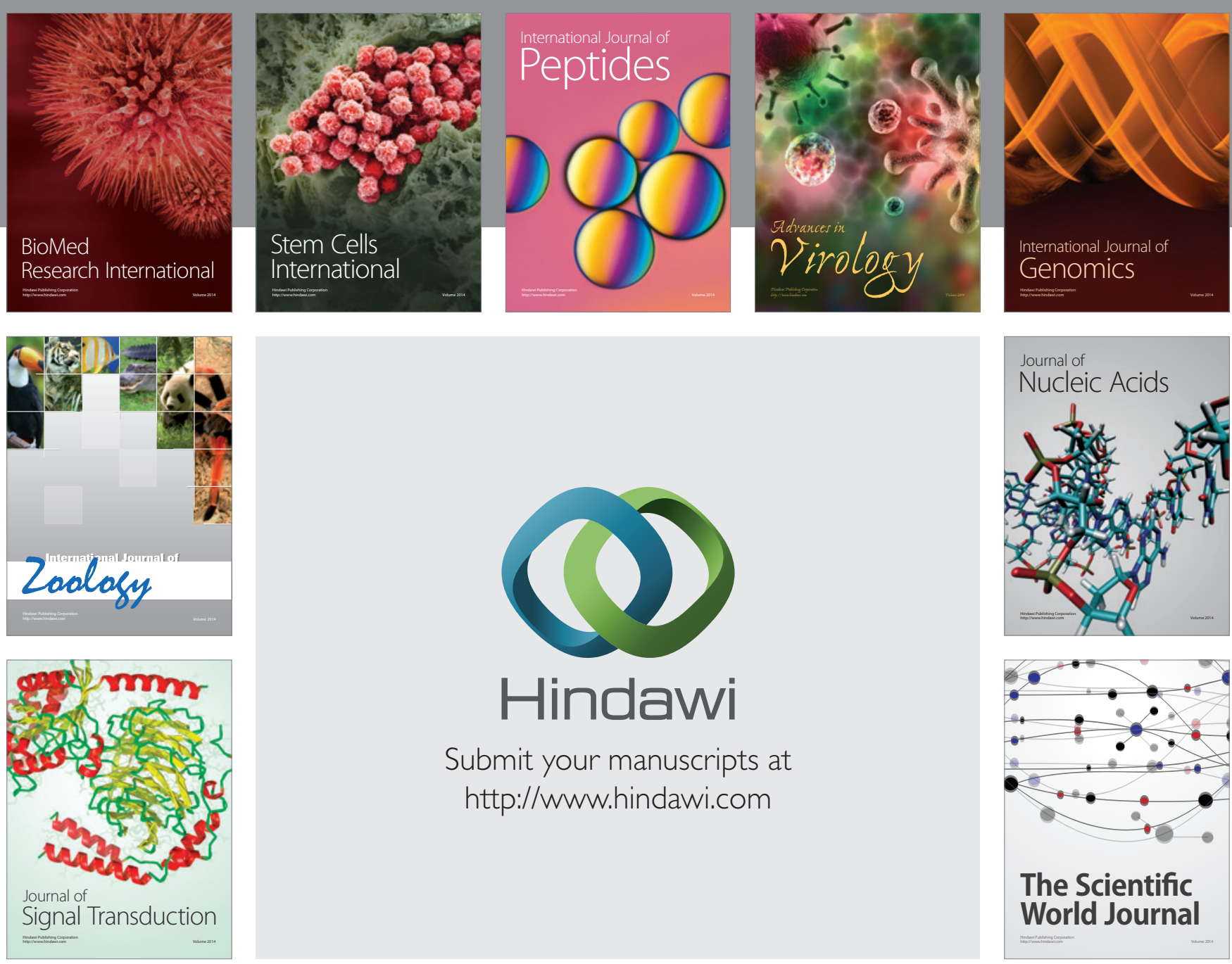

Submit your manuscripts at

http://www.hindawi.com
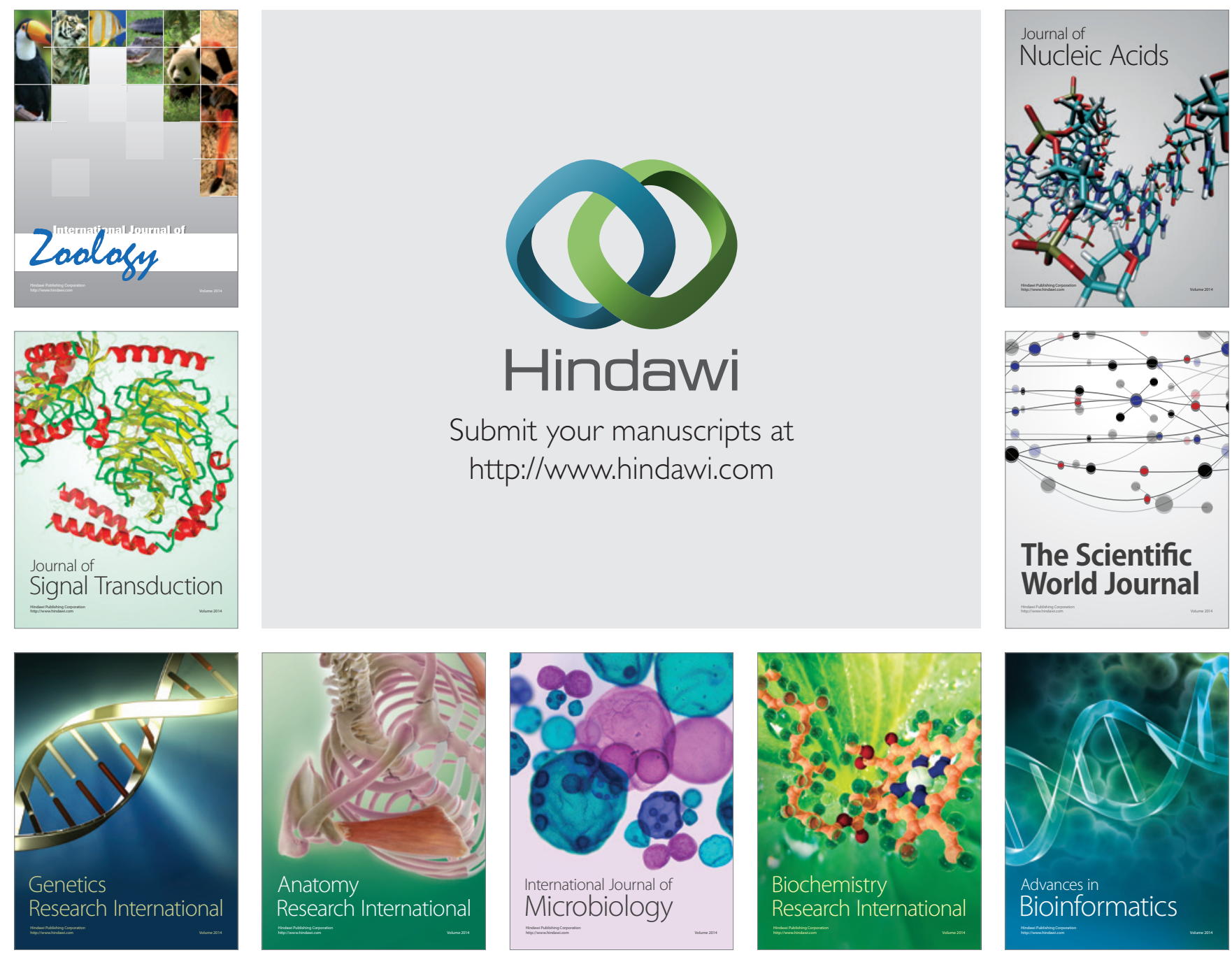

The Scientific World Journal
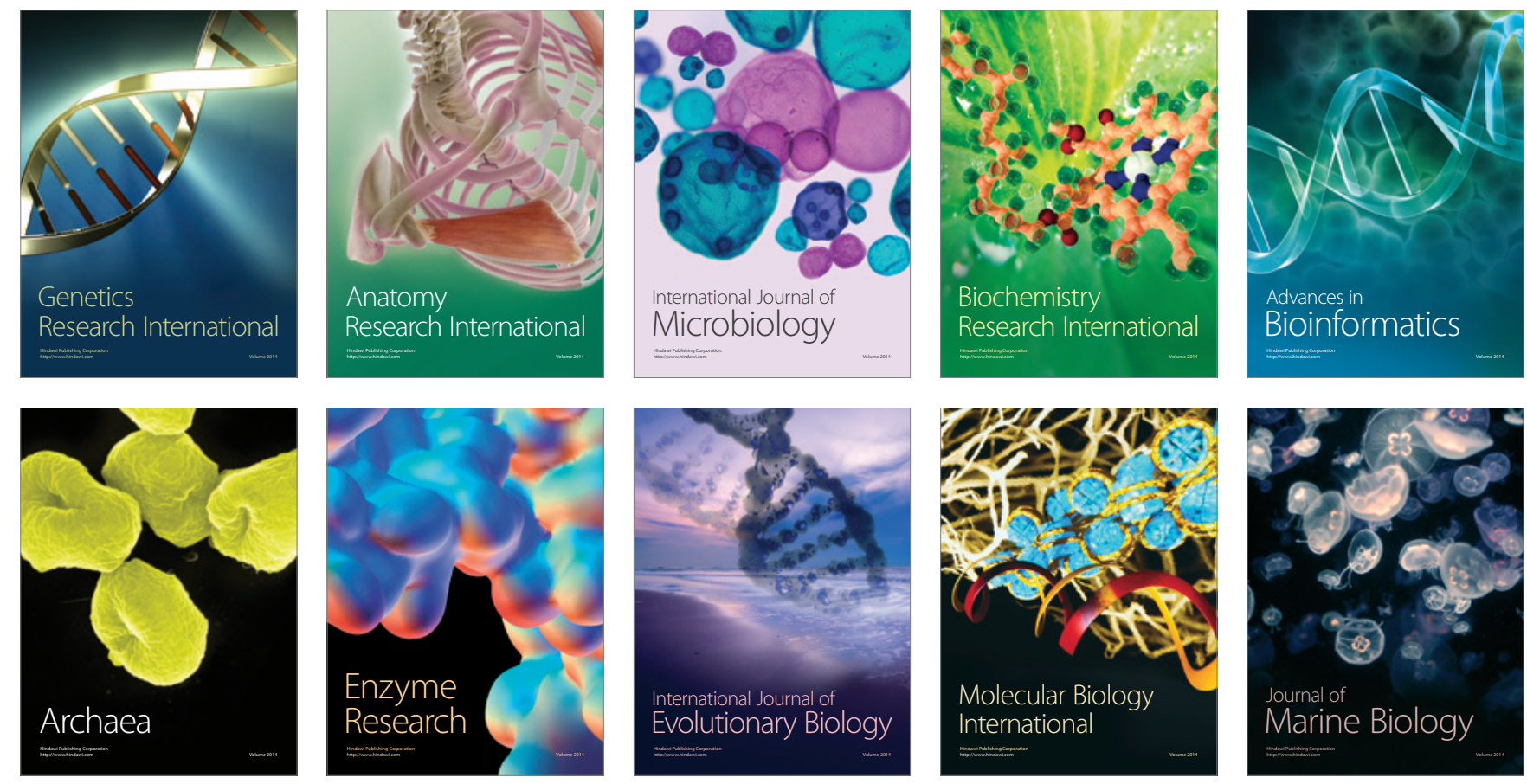